\title{
Studying combined effects of chemotherapy and radiotherapy on blood cell counts in lung cancer patients
}

\author{
Muhammad Imran ${ }^{1}$, Muhammad Iqbal ${ }^{2 *}$, Abu Sufyan ${ }^{2}$, Samina Ejaz $^{2}$, \\ Muhammad Yasir Zahoor ${ }^{3}$, Muhammad Adnan ${ }^{4}$, Muhammad Zohaib \\ Shah $^{2}$ and Aziz ur Rehman \\ 1. Department of Chemistry, Ghazi University, Dera Ghazi Khan-Pakistan \\ 2. Department of Biochemistry and Biotechnology, The Islamia University of Bahawalpur-Pakistan \\ 3. Institute of Biochemistry and Biotechnology, University of Veterinary and Animal Sciences, Lahore-Pakistan \\ 4. Sheikh Zaid Medical College, Rahim Yar Khan-Pakistan \\ 5. Bahawalpur Institute of Nuclear Medicine and Oncology, Bahawalpur-Pakistan \\ *Corresponding author's email: Iqbal.khawaja@iub.edu.pk \\ Citation \\ Muhammad Imran, Muhammad Iqbal, Abu Sufyan, Samina Ejaz, Muhammad Yasir Zahoor, Muhammad Adnan, \\ Muhammad Zohaib Shah and Aziz ur Rehman. Studying combined effects of chemotherapy and radiotherapy on \\ blood cell counts in lung cancer patients. Pure and Applied Biology. Vol. 6, Issue 3, pp1002-1009. \\ http://dx.doi.org/10.19045/bspab.2017.600106
}

Received: 10/02/2016 Revised: 20/08/2017

Accepted: $28 / 08 / 2017$

Online First: 04/09/2017

\section{Abstract}

Lung cancer is the main cause of cancer death both in males and females. There are two major classes of lung cancer; small cell lung carcinoma (SCLC) and non-small cell lung carcinoma (NSCLC). About $98 \%$ of SCLC is due to cigarette smoking. Mutation in epidermal growth factor gene and translocation in anaplastic lymphoma kinase gene have a crucial role in pathogenesis of some lung cancers. For small cell lung cancer chemotherapy is best technique but for non-small cell lung cancer techniques go from surgery to chemotherapy according to the stage of disease. The effects of chemotherapy and radiotherapy were examined by taking blood samples from 59 patients of lung cancer. These patients were categorized according to gender and age. After therapies blood cell counts were going to normal values while somewhere deviations were also observed. Positive effects of radiotherapy are limited to the area of radiation focused. The common side effects are sore throat, tiredness, hair loss, feeling sick and temperature. Non small lung cancer patients have symptoms like weight loss, shortness of breath and fatigue. The results of therapy not only increase the quality of life but it also minimizes the symptoms.

Keywords: Carcinoma; Chemotherapy; Fatigue; Prostate cancers; Anaplastic lymphoma kinase

\section{Introduction}

Lung cancer is the main cause of cancer death both in males and females. Death rate due to lung cancer is more than colon, breast and prostate cancers [1]. World Health Organization has classified lung cancer into four main types; (a) squamous cell (epidermoid) carcinoma, (b) small-cell (oat cell) carcinoma, (c) adenocarcinoma, and (d) large cell carcinoma.

Based upon therapy, biology and prognosis lung cancer is divided into two major 
classes; small cell lung carcinoma (SCLC) and non-small cell lung carcinoma (NSCLC) [2]. Non-small cell lung carcinoma accounts for $75 \%$ to $80 \%$ of all lung cancers whereas small cell lung carcinoma accounts for $15 \%$ to $25 \%$. About $98 \%$ of SCLC is due to cigarette smoking [3-5]. Approximately 10 $20 \%$ of lung cancers develop in nonsmokers (<100 cigarettes/lifetime) [6]. The research on lung cancer during last decade has provided significant advances in the understanding of molecular pathways involved in carcinogenesis and in the development of targeted therapies. Mutations in the gene encoding epidermal growth factor receptor (EGFR) and translocations involving the anaplastic lymphoma kinase (ALK) gene play important role in the pathogenesis of some lung cancers, predominantly in nonsmokers. The findings showed improved results with tyrosine kinase inhibitors (TKIs) focusing these aberrant oncogenes [7]. The poor survival rate of patients is due to its diagnosis at advanced stage. The most contributing factor is the methylation of DNA at promoter region in tumor suppressor gene. In the early stage of carcinogenesis, promoter methylation of these genes are found and remain during progression [8].

More than $80 \%$ of patients with NSCLC at some times during the course of their disease are potential candidates for systemic chemotherapy [9]. Several factors related to lung cancer patients, stages of disease and treatment characteristics affect the quality of life (QOL). For small cell lung cancer (SCLC) treatment primarily is based on the chemotherapy but for NSCLC, treatment is strongly based on the stage of disease and can be chemotherapy or surgery or both [10].

Radiotherapy is the most common therapeutic strategy to treat lung cancer. Positive effects of radiotherapy are limited to the area of radiation focused. It may affect the normal tissues of healthy body and these effects are of long term duration. The common side effects of radiotherapy are sore throat, tiredness, feeling run down, hair loss, difficulty in swallowing, cough, temperature, shivering, chest pain, feeling sick and sore skin [11, 12]. Gamma $(\gamma)$ radiation of high energy is used to shrink or kill the cancerous cells by breakage of DNA [13]. $\gamma$-radiation cause single strand and double strand breakage in DNA which finishes with mutation and chromosomes aberrations (CAs) [14]. It also causes the enzyme inactivation which break the chemical bonds, cross linking and structural degradation [15]. In a study adverse events of any grade have been found in $71 \%$ of the patients who received nivolumab as subsequent therapy and in $92 \%$ of those who received chemotherapy [16].

For the patient with small cell carcinoma, radiation therapy and chemotherapy are the best technique. Chemotherapy combined with radiotherapy has improved the survival of patients with small cell carcinoma. Patients with advanced NSCLC often have symptoms like weight loss, shortness of breath, pain, fatigue and loss of appetite, so the result of therapy not only increases the duration of life but also minimizes the symptoms and improves quality of life (QoL) [17]. The significance of QoL as a treatment result is recognized by the American Society of Clinical Oncology and the United States Food and Drug Administration [18, 19]. In the body fluids of lungs cancer patients there is higher concentration of lipid peroxidation products which may outcome of systemic oxidative stress. Malondialdehyde (MDA) is one of the most important end products of lipid per oxidation. Its plasma level was higher than the healthy ones when matched $[20,21]$. 1.35 million people were diagnosed in 2002 
approximately with lungs cancer and 1.15 million people died from the disease [22].

\section{Materials and methods}

150 patients with lung cancer who visited BINO Cancer Hospital Bahawalpur were enrolled for study. These patients belonged to southern Punjab districts; Bahawalpur, Rahim Yar Khan, Lodhran, Vehari and Rajanpur. Blood samples were collected aseptically from each patient into tripotassium (EDTA) ethylene diamine tetra acetic acid anticoagulant test tubes. This was well mixed by a gentle inversion for complete blood count analyses. The study of blood samples of lung cancer patients were conducted in a routine pathology laboratory at the BINO Cancer Hospital, Bahawalpur Pakistan. Complete blood cell count (CBC) was analysed by an automated method using hematology auto analyzer Sysmex KX-21 N. The automated analysis was done following the manufacturer's operational guidelines. All blood samples of lungs cancer patients were analyzed within 30 minutes of collection. Four parameters were examined WBCs, RBCs, Hb and PLTs. The data of lungs cancer patient's blood samples for variations in blood cell counts after consecutive chemotherapy and radiotherapy were recorded.

\section{Results}

Chemotherapy and radiotherapy effects on 59 Lung Cancer patients (55 males and 4 females) including both types; small cell lung carcinoma (SCLC) and non-small cell lung carcinoma (NSCLC) were analyzed after two consecutive therapies. The count of blood cells were observed little bit higher than normal in some patients. Before therapy in male patients, WBCs count was higher than the normal value and RBCs, HGB and PLTs counts were in normal range except in some patients where PLT and HGB were observed below to the normal limit. Before chemotherapy platelets counts was at maximum value of 800 and after chemotherapy it was at maximum value of 1600. After chemotherapy some patients also showed the platelets count 600 to 1000 . There was no significant change in HGB and RBCs in majority patients. There was decrease in WBCs count in patients. Some patients showed increase in WBCs counts but maximum of patients showed decrease in WBCs count. Maximum HGB value before chemotherapy was 6.8 and after chemotherapy maximum value showed by patients was 9.4 (Figure 1).

After $1^{\text {st }}$ treatment WBCs had been observed going to normal value but there was little deviation in RBCs, PLTs and HGB values in male patients. There was decrease in maximum value of WBCs after consecutive therapies. In the patients both below 50 years of age and above 50 years of age, WBCs count lowered going to normal value after therapies. There was no much more disturbance in RBCs and PLTs but HGB values were going to normal value after therapies.

In females the effect of treatment was observed randomly at patients. In females after 1st treatment average of WBCs became lower than before treatment and after 2nd treatment it was observed again higher. And after $1 \mathrm{st}$ and 2nd treatments increase in maximum were observed while deviations in minimum were observed. After 2nd treatment the range of blood counts (WBCs, RBCs and HGB) except PLTs was observed more than before treatment and after 1st treatment. The results of Chi test from 1st to before treatment and from second to $1^{\text {st }}$ treatment were increasing and becoming to 1 (Table 1 and Table 2).

In the patients of 50 years and above 50 years of age, WBCs from lowered value were going to normal value after therapies. Similarly there were no much more disturbance in RBCs and HGB but PLTs from lowered value were going to normal 
value. And their effects on patients were favorable to treatment because blood counts were observed coming to normal values.

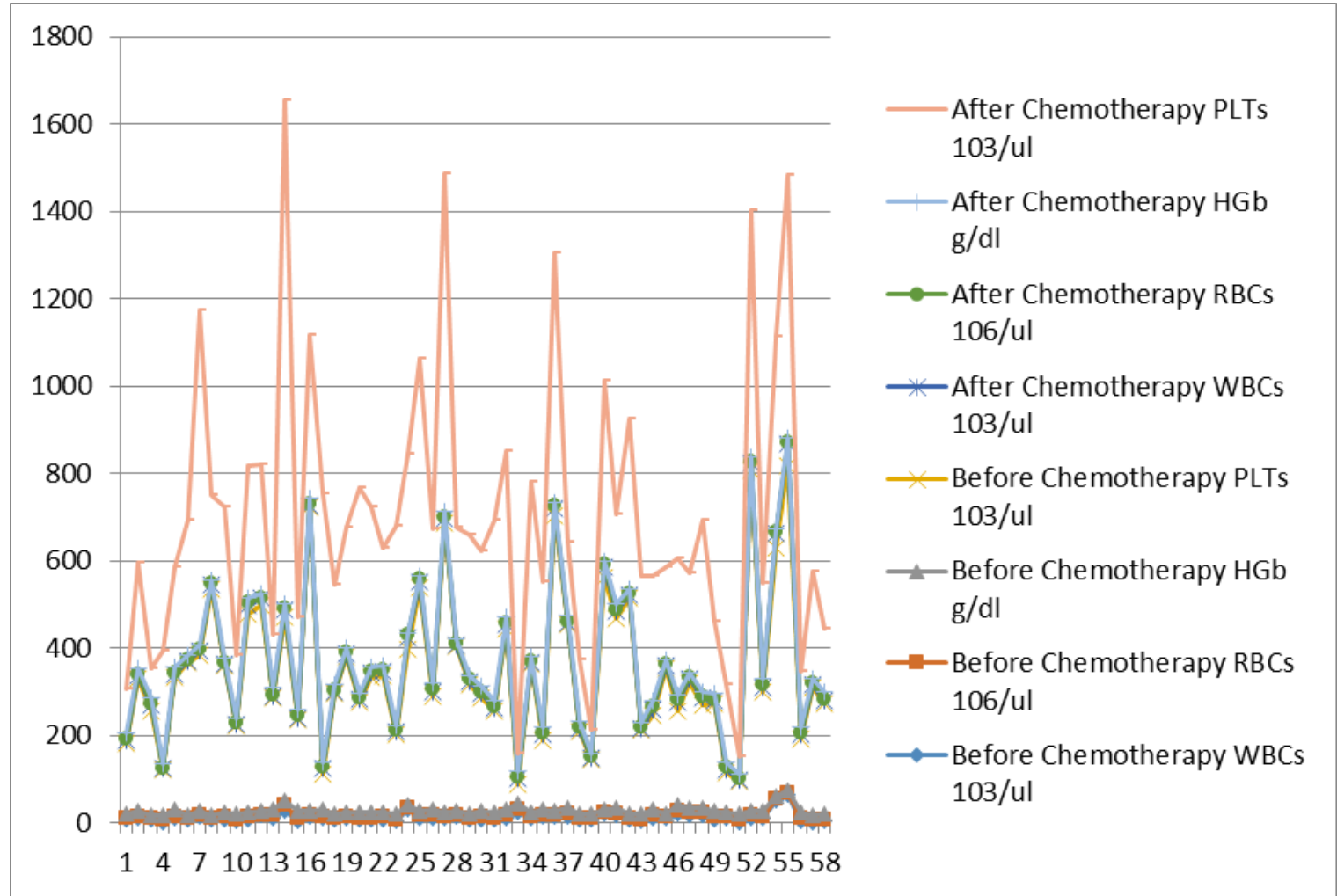

Figure 1. Graph showing blood cell count before and after chemotherapy and radiotherapy

Table 1. Showing blood cell count and statistical analysis before treatment

\begin{tabular}{|l|l|l|l|l|}
\hline Blood Cell Type & $\begin{array}{l}\text { WBCs } \\
\mathbf{1 0} / \mathbf{u l}\end{array}$ & $\begin{array}{l}\text { RBCs } \\
\mathbf{1 0} / \mathbf{l} \mathbf{l}\end{array}$ & $\begin{array}{l}\text { HGB } \\
\text { g/dl }\end{array}$ & $\begin{array}{l}\text { PLTs } \\
\mathbf{1 0} / \mathbf{u l}\end{array}$ \\
\hline Average & 12.34372881 & 4.486102 & 1.705027 & 324.0677966 \\
\hline Maximum & 65.5 & 12.42 & 15.5 & 780 \\
\hline Minimum & 1.7 & 2.28 & 6.7 & 44 \\
\hline Median & 10.4 & 4.47 & 11.7 & 293 \\
\hline Mode & 8.8 & 4.64 & 11.2 & 251 \\
\hline Standard deviation & 10.71989094 & 1.370634 & 2.149737 & 167.9477407 \\
\hline Chitest 1st to before treatment & $8.06779 \mathrm{E}-20$ & 1 & 1 & 0 \\
\hline
\end{tabular}

Table 2. Showing blood cell count and statistical analysis after1st treatment

\begin{tabular}{|l|l|l|l|l|}
\hline Blood Cell type & $\begin{array}{l}\text { WBCs } \\
\mathbf{1 0} / \mathbf{u l}\end{array}$ & $\begin{array}{l}\text { RBCs } \\
\mathbf{1 0} / \mathbf{u l}\end{array}$ & $\begin{array}{l}\text { HGB } \\
\text { g/dl }\end{array}$ & $\begin{array}{l}\text { PLTs } \\
\mathbf{1 0} / \mathbf{u l}\end{array}$ \\
\hline Average & 10.52474576 & 4.275254 & 11.03712 & 322.5254237 \\
\hline Maximum & 47.7 & 6.75 & 15.4 & 1154 \\
\hline Minimum & 1 & 2.05 & 6.5 & 39 \\
\hline Median & 8.2 & 4.37 & 11 & 304 \\
\hline Mode & 13.8 & 4.75 & 10.3 & 312 \\
\hline Standard deviation & 8.112073241 & 0.879924 & 2.08644 & 195.6421219 \\
\hline Chitest 2nd to 1st treatment & $5.0201 \mathrm{E}-17$ & 0.999997 & 1 & 0 \\
\hline
\end{tabular}




\section{Discussion}

At present, chemotherapy is one of the important approaches in treating malignant tumors.

In present study the patients of both types of lung cancer; small cell lung cancer and nonsmall cell lung cancer were included. The combined effects of chemotherapy and radiotherapy on CBCs count of lung cancer patients of both types were observed. There was not much more change in the blood cells count after chemotherapy and radiotherapy. In some patients it was observed lower than normal. So during lung cancer blood count not much more disturbed. The count of blood cells were observed little bit higher than normal in some patients. And in very least patients it was observed lower than normal. So during lung cancer blood count not much more disturbed. The effects of chemotherapy and radiotherapy at patients were favorable to treatment because blood counts were observed coming to normal.

In female patients after 1st treatment average of WBCs became lower than before treatment and after 2nd treatment it was observed again higher. And after 1st and 2nd treatment, increase in maximum were observed while deviations in minimum were observed. After $2^{\text {nd }}$ treatment, range of blood counts (WBCs, RBCs and HGB) was observed more than before treatment and after $1^{\text {st }}$ treatment except PLTs. More males had been seen than females in lung cancer patients. A small number of female patients with lung cancer were enrolled in the BINO Cancer Hospital, Bahawalpur Pakistan during study period. Therefore only 4 female patients are included in the study while 55 males having lung cancer are included in the present study. In male patients WBCs were observed more than normal before treatment while RBCs, HGB and PLTs were round about to normal except in some patients where PLT and HGB were observed below to normal limit. In the patients below 50 years of age WBCs were also lowered going to normal value after therapies. No much more disturbance in RBCs and PLTs but HGB going to normal value after therapies was noted. In the patients of 50 years and above, WBCs from lowered value was going to normal value after therapies. There were no much more disturbance in RBCs and HGB but PLTs from lowered value were going to normal value. More males had been seen than females in lung cancer patients. In female patients the minimum values were also lowered going to normal value. There is no much more disturbance in median and mode value of WBCs and these are in the range of normal value. So we can say that in lung cancer patients the value of WBCs come to normal value after therapies. The results presented in this study can be compared with previous reports. In a study no significant associations was found between baseline CTC counts and clinical characteristics including age, sex, smoking history, metastases and stage at diagnosis [23]. In another study effects of chemotherapy and radiotherapy on two groups of cancer patients were observed. There was most significant decrease (more than $25 \%$ ), in CBC parameters in the group treated by radiotherapy [24]. The acute side effects of combined chemotherapy and radiotherapy on the blood cells count can dysfunction the proliferation and differentiation processes which are associated with the recovery of these blood cells [25]. In a study, the lymphocyte percentage increased during chemotherapy, at a significant difference with respect to the pretreatment values but after the first chemotherapeutic cycle, significantly decreased in these patients [26]. The lymphocytes produce in the bone-marrow, and if the function of the bone-marrow 
depresses, a low lymphocyte count will be reported. Anemia is a common problem in many cancer types related to chemotherapy with radiotherapy. In a study, [27] estimated the average survival duration reduced up to $20-43 \%$ in $33 \%$ patients who were anemic. It was also reported that $48 \%$ of patients who were treated for radiotherapy for solid tumors; were anemic before treatment and this had increased up to $57 \%$ at the end of therapy [28-30]. Significant difference of WBCs and RBCs was observed in between those cancer patients who were treated with both chemotherapy and radiotherapy and those cancer patients who were treated only with the radiotherapy [31]. The peripheral blood lymphocytes in chemotherapy receiving cancer patients were analyzed and found that monocytes, neutrophils and platelet counts though recovered more than $50 \%$ after each cycle of therapy, the lymphocyte counts did not recover within the same time interval of the course [32]. So the results presented in this study are consistent with the previous reports.

\section{Conclusion}

Chemotherapy and Radiotherapy do not have much more disturbance in RBCs and PLTs count rather after therapies HGB and blood cell count came to normal values.

\section{Authors' contributions}

Conceived and designed the experiments: $\mathrm{M}$ Imran \& M Iqbal, Performed the Experiments: A Sufyan \& M Z Shah, Analyzed the Data: S Ejaz, M Y Zahoor \& M Adnan, Contributed reagents/ materials/ analysis tools: AU Rehman, Wrote the paper: M Iqbal.

\section{References}

1. American Cancer Society. http://www.cancer.org 2005.

2. Ettinger DS, Beple G \& Cox JD (2002). Non-small cell lung cancer. National Comprehensive Cancer Network, Inc. Version 1.
3. Bruce E, Johnson, Athanassios A \& Robert J (2002). Small cell lung cancer. National Comprehensive Cancer Network.

4. Travis WD, Colby TV \& Corrin B (1999). Histological typing of lung and pleural tumors. Berlin: Springer-Verlag.

5. Simon G, Ginsberg RJ \& Ruckdeschel JC (2001). Small-cell lung cancer. Chest surgery clinics of North America 11: 165188, ix.

6. Sun S, Schiller JH \& Gazdar AF (2007). Lung cancer in never smokers--a different disease. Nature reviews. Cancer 7: 778790.

7. Gaughan EM \& Costa DB (2011). Genotype-driven therapies for non-small cell lung cancer: focus on EGFR, KRAS and ALK gene abnormalities. Therapeutic advances in medical oncology 3: 113-125.

8. Dong SM, Lee EJ, Jeon ES, Park CK \& Kim KM (2005). Progressive methylation during the serrated neoplasia pathway of the colorectum. Modern pathology : an official journal of the United States and Canadian Academy of Pathology Inc 18: 170-178.

9. Shepherd FA (1994). Treatment of advanced non-small cell lung cancer. Seminars in oncology 21: 7-18.

10. Gridelli C, Perrone F, Nelli F, Ramponi S \& De Marinis F (2001). Quality of life in lung cancer patients. Annals of oncology : official journal of the European Society for Medical Oncology 12 Suppl 3: S21-25.

11. Faulhaber O \& Bristow RG (2005) Basis of cell kill following clinical radiotherapy. Application of apoptosis to cancer treatment (Ed.: M.Sluyser). Springer Berlin 293-320.

12. www.cancerhelp.or.uk, 2008.

13. Manda K \& Bhatia AL (2003). Preadministration of beta-carotene protects tissue glutathione and lipid peroxidation 
status following exposure to gamma radiation. Journal of environmental biology 24: 369-372.

14. Natarajan AT (2002). Chromosome aberrations: past, present and future. Mutation research 504: 3-16.

15. Shacter E (2000). Quantification and significance of protein oxidation in biological samples. Drug metabolism reviews 32: 307-326.

16. Carbone DP, Reck M, Paz-

Ares L, Creelan B, Horn L, Steins M, Fe lip E, van den

Heuvel MM, Ciuleanu TE, Badin F, Rea dy N, Hiltermann TJN, Nair S, Juergens

R, Peters S, Minenza E, Wrangle JM, Ro driguez-

breu D, Borghaei H, Blumenschein

GR Jr, Villaruz LC, Havel L, Krejci J, Ja ime CJ, Chang H, Geese WJ, Bhagavath eeswaran P, Chen AC \& Socinski MA(2017). First-Line Nivolumab in Stage IV or Recurrent Non-Small-Cell Lung Cancer. $N$ Engl $J$ Med 376(25): 2415-2426.

17. Montazeri A, Gillis CR \& McEwen J (1998). Quality of life in patients with lung cancer: a review of literature from 1970 to 1995 . Chest 113: 467-481.

18. Beitz J, Gnecco C \& Justice R (1996). Quality-of-life end points in cancer clinical trials: the U.S. Food and Drug Administration perspective. Journal of the National Cancer Institute Monographs 7-9.

19. American Society of Clinical Oncology (1996). Outcomes of cancer treatment for technology assessment and cancer treatment guidelines. American Society of Clinical Oncology. Journal of clinical oncology : official journal of the American Society of Clinical Oncology 14: 671-679.

20. Gonenc A, Ozkan Y, Torun M \& Simsek B (2001). Plasma malondialdehyde (MDA) levels in breast and lung cancer patients. Journal of clinical pharmacy and therapeutics 26: 141-144.

21. Look MP \& Musch E (1994). Lipid peroxides in the polychemotherapy of cancer patients. Chemotherapy 40: 8-15.

22. Coleman MP, Quaresma M, Berrino F, Lutz JM, De Angelis R, Capocaccia R, Baili P, Rachet B, Gatta G, Hakulinen T, Micheli A, Sant M, Weir HK, Elwood JM, Tsukuma H, Koifman S, GA E S, Francisci S, Santaquilani M, Verdecchia A, Storm HH, \& Young JL (2008). Cancer survival in five continents: a worldwide population-based study (CONCORD). The Lancet. Oncology 9: 730-756.

23. Shen J, Zhao J, Jiang T, Li X, Zhao C, Su C \& Zhou C (2017). Predictive and prognostic value of folate receptorpositive circulating tumor cells in small celllung cancer patients treated with first-line chemotherapy. Oncotarget (Online Published).

24. Cooper JS, Pajak, TF, Forastiere A A, Jacobs J, Campbell BH, Saxman SB, Kish JA, Kim HE, Cmelak AJ \& Rotman M (2004). Postoperative concurrent radiotherapy and chemotherapy for high-risk squamouscell carcinoma of the head and neck . New Engl J Med 350: 1937-1944.

25. Kovacs C, Evans M \& Daly B (2005). A hematopoietic stromal lesion associated with fractionated radiotherapy (FxRT): time-and dose-effects. Anticancer Res 25: 2801-2807.

26. Lissoni P1, Fumagalli L, Paolorossi F \& Mandalà M (1999). Changes in lymphocyte number during cancer chemotherapy and their relation to clinical response. Int $\mathrm{J}$ Biol Markers 14(2):115-7.

27. Caro JJ, Salas M, Ward A \& Goss G (2001). Anemia as an independent prognostic factor for survival in patients with cancer. Cancer 9: 2214-2221. 
28. Demetri G (2001). Anaemia and its functional consequences in cancer patients: current challenges in management and prospects for improving therapy. Br J Cancer 84: 31

29. Doni L, Perin A, Manzione L, Gebbia V, Mattioli R, Speranza GB, Latini L, Iop A, Bertetto O \& Ferraù F (2011). The impact of anemia on quality of life and hospitalisation in elderly cancer patients undergoing chemotherapy. Crit Rev Oncol Hematol 77:70-77.

30. Fallowfield L, Gagnon D, Zagari M, Cella D, Bresnahan B, Littlewood T, McNulty P, Gorzegno G \& Freund M (2002). Multivariate regression analyses of data from a randomised, double-blind, placebo-controlled study confirm quality of life benefit of epoetin alfa in patients receiving non-platinum chemotherapy. Br J Cancer 87: 1341-1353.

31. Henry D H, Dahl N V, Auerbach M, Tchekmedyian S \& Laufman LR (2007). Intravenous ferric gluconate significantly improves response to epoetin alfa versus oral iron or no iron in anemic patients with cancer receiving chemotherapy.Oncologist 12: 231-242.

32. Mackall CL, Fleisher TA, Brown MR, Magrath IT, Shad AT, . Horowitz ME, Wexler LH, Adde MA, McClure LL \& Gress RE (1994). Lymphocyte depletion during treatment with intensive chemotherapy for cancer. Blood 84: 2221-2228. 